\title{
Nitric Oxide/Protein Kinase G-la Promotes c-Src Activation, Proliferation and Chemoresistance in Ovarian Cancer
}

\author{
Ronald R. Fiscus ${ }^{1,2}$, Elaine L. Leung1,2,3, \\ Janica C. Wong $1,2,4$ and Mary G. Johlfs ${ }^{1,2}$ \\ ${ }^{1}$ Center for Diabetes and Obesity Prevention, Treatment, Research and \\ Education, and the College of Pharmacy, Roseman University of \\ Health Sciences (Formerly University of Southern Nevada), Henderson, Nevada, \\ ${ }^{2}$ Cancer Molecular Biology Section, Nevada Cancer Institute, Las Vegas, Nevada, \\ ${ }^{3}$ State Key Laboratory for Quality Research in Chinese Medicines, Macau University of \\ Science and Technology, Taipa, Macau Special Administrative Region, \\ and Shum Yiu Foon Shum Bik Chuen Memorial Centre for Cancer and Inflammation \\ Research, School of Chinese Medicine, Hong Kong Baptist University, and \\ Department of Pathology, Faculty of Medicine, The University of Hong Kong, \\ Hong Kong Special Administrative Region, \\ ${ }^{4}$ Department of Chemistry, University of Nevada Las Vegas, Las Vegas, Nevada, \\ $1,2,4$ USA \\ ${ }^{3}$ China
}

\section{Introduction}

Ovarian cancer is often associated with the development of resistance to chemotherapeutic agents (chemoresistance) and a recurrence of tumor growth, making this type of cancer especially difficult to treat by chemotherapy (Chien et al, 2007). The exaggerated cell growth and chemoresistance of ovarian cancer cells involve the dysregulation of multiple cell signaling (signal transduction) pathways that normally regulate cell proliferation and cell survival (Fraser et al, 2003). One particular cell signaling pathway that has recently become recognized as playing a central role in promoting cell proliferation and chemoresistance in human ovarian cancer cells is the nitric oxide (NO)/cyclic GMP (cGMP)/cGMP-dependent protein kinase [protein kinase G (PKG)] pathway (Fraser et al, 2006; Leung et al, 2008; Leung et al, 2010). Interestingly, two of the risk factors for developing ovarian cancer, i.e. advanced age and diabetes/obesity (Kulie et al, 2011), are known to cause dramatic dysregulations at multiple steps in the NO/cGMP/PKG signaling pathway in various organ systems, most notably the cardiovascular system (e.g. severe impairment of NO-mediated vasodilation and anti-hypertensive effects of the neuropeptide CGRP) (Chan \& Fiscus, 2002; Fiscus et al, 2001; Fiscus \& Ming, 2000; Fung et al, 2005) and the male reproductive system (e.g. diminished penile erection normally mediated by NO/cGMP/PKG signaling) (Fiscus, 2002; Fiscus et al, 2001; Fiscus \& Ming, 2000; Fung et al, 2005). This dysregulation of the 
$\mathrm{NO} / \mathrm{cGMP} / \mathrm{PKG}$ pathway contributes to the pathogenesis of various aging- and diabetes/ obesity-induced pathological complications, including hypertension, atherosclerosis and erectile dysfunction (Fiscus, 1988; Fiscus, 2002; Fiscus et al, 2001; Fiscus \& Ming, 2000; Fung et al, 2005). However, until recently, the role of this signaling pathway in the pathogenesis of ovarian cancer had remained unrecognized. Recent data from our laboratory have now shown that the NO/cGMP/PKG signaling pathway, specifically involving the PKG type-I $\alpha$ (PKG-I $\alpha$ ) isoform of PKG and its interaction with the c-Src tyrosine kinase pathway, plays a key role in promoting the exaggerated cell proliferation and chemoresistance in human ovarian cancer cells (Fraser et al, 2006; Leung et al, 2008; Leung et al, 2010).

Many of the early studies of NO in ovarian cancer had suggested that this small molecule mediates tumoricidal activity, including showing that $\mathrm{NO}$ donors added to ovarian cancer cells in vitro or the induction of high-level $\mathrm{NO}$ synthesis within the ovarian cancer cells by exposure to pro-inflammatory cytokines results in increased levels of apoptotic cell death (Cantuaria et al, 2000; Garban \& Bonavida, 1999; Rieder et al, 2001). Furthermore, NO, released from activated macrophages, inhibits the growth of tumors in an animal model of ovarian cancer (Farias-Eisner et al, 1994). However, the molecular mechanisms mediating these tumoricidal actions of NO were not determined in the early studies. It is now recognized that $\mathrm{NO}$ has multiple actions in mammalian cells, including both toxic and cytoprotective effects, which greatly depend on the local concentration of NO and the microenvironmental conditions (e.g. whether there is a co-presence of elevated levels of superoxide, which can combine with high-level NO to form peroxynitrite, a toxic prooxidant mediating both oxidative and nitrosative stress) (Cheng Chew et al, 2003; Fiscus, 2002; Fiscus et al, 2002; Leung et al, 2008; Wong \& Fiscus, 2010; Wong \& Fiscus, 2011).

At lower physiological levels (0.01 - 1 nanomolar), NO selectively activates the PKG-I $\alpha$ isoform (Batchelor et al, 2010; Nausch et al, 2008; Sato et al, 2006), which our laboratory has shown results in cytoprotection (i.e. inhibition of multiple steps in pro-apoptosis pathways, preventing both spontaneous and toxin-induced apoptosis) as well as stimulation of DNA synthesis and cell proliferation in many mammalian cells, including human ovarian cancer cells (Chan \& Fiscus, 2003; Cheng Chew et al, 2003; Fiscus, 2002; Fiscus et al, 2002; Fraser et al, 2006; Fung et al, 2005; Leung et al, 2008; Leung et al, 2010; Wong \& Fiscus, 2010; Wong \& Fiscus, 2011). Although earlier studies had reported that "PKG expression is lost" when ovarian epithelial cells transform into cancer cells (Hou et al, 2006; Wong et al, 2001), our studies show that human ovarian cancer cells do indeed express PKG-I $\alpha$, which contributes to exaggerated cell proliferation and chemoresistance (Leung et al, 2008; Leung et al, 2010).

At higher concentrations (>100 nanomolar), as used in the earlier studies mentioned above, NO causes cytotoxic effects in many types of mammalian cells, both normal and cancer cells, which can involve both the direct S-nitrosylation of cysteine residues of proteins, altering their function (Nakamura \& Lipton, 2010; Seth \& Stamler, 2011), and the indirect nitration of tyrosine residues in proteins (via formation of peroxynitrite), further altering protein function (e.g. interferring with tyrosine phosphorylation) (Beckman \& Koppenol, 1996; Fiscus, 2002; Fiscus et al, 2002; Ridnour et al, 2008; Thomas et al, 2008). Details of these cellular/molecular mechanisms mediating the concentration-dependent cytoprotective and cytotoxic actions of $\mathrm{NO}$ are discussed below and illustrated in the following figures. 


\section{Early studies identifying the important roles of NO, cGMP and PKG in controlling blood pressure and blood flow and mediating penile erection}

Endogenous NO [originally referred to as EDRF (endothelium-derived relaxant factor)] in the cardiovascular system was first shown to play an important biological role in regulating arterial diameter [for reviews, see (Fiscus, 1988; Fiscus, 2002; Francis et al, 2010; Hofmann et al, 2006; Lincoln et al, 2001; Pilz \& Casteel, 2003)]. In healthy arteries (i.e. arteries from individuals that are young and without diabetes, obesity or hypertension), endogenous NO is produced at physiological levels, now estimated to be in the range of $0.01-10$ nanomolar (Batchelor et al, 2010; Sato et al, 2006), by the endothelial-form NO-synthase (eNOS) within the endothelial cells lining the arteries. Because of its high lipid solubility, NO readily diffuses into nearby cells, importantly vascular smooth muscle cells in blood vessels, where $\mathrm{NO}$, via binding to the heme group of soluble guanylyl cyclase, enhances cGMP synthesis, resulting in elevation of intracellular levels of cGMP and activation of PKG.

Early studies throughout the 1970's and early 1980's, using purified PKG in in vitro experiments, had shown that the addition of cGMP to the purified PKG could enhance its kinase activity, suggesting that cGMP may be the intracellular chemical that serves as the allosteric activator of PKG within cells, similar to the role of cAMP in activating CAMPdependent protein kinase (protein kinase A, PKA) [reviewed in (Fiscus, 1988; Fiscus, 2002; Francis et al, 1988; Hofmann et al, 2006; Lincoln et al, 2001; Pilz \& Casteel, 2003)]. Thus, early on, it was suggested that NO, via its ability to elevate intracellular cGMP levels, may be causing vascular effects by activating PKG within the smooth muscle cells. However, the early attempts to prove this were found to be exceedingly difficult because of the uniquely unstable nature of the PKG activation that occurs within mammalian cells (Fiscus, 1988; Fiscus, 2002; Fiscus \& Murad, 1988; Fiscus et al, 1983; Fiscus et al, 1984). It was not until 1983 and 1984 that NO was first shown to significantly stimulate the intracellular activation state of PKG in mammalian cells (Fiscus et al, 1983; Fiscus et al, 1984).

As a serine/threonine kinase, PKG phosphorylates numerous downstream target proteins in vascular smooth muscle cells, which ultimately results in the suppression of arterial vasoconstriction (i.e. vasodilation) (Fiscus, 1988; Fiscus, 2002; Fiscus \& Murad, 1988; Francis et al, 1988; Hofmann et al, 2006; Lincoln et al, 2001; Pilz \& Casteel, 2003). The $\mathrm{NO} / \mathrm{cGMP} / \mathrm{PKG}$ signaling pathway in vascular smooth muscle cells plays an essential role in preventing vasospasms and maintaining normal blood pressure and blood flow. Interestingly, even the basal release of NO from healthy endothelial cells, now estimated to generate a local concentration of NO of 0.01 - 0.1 nanomolar (Batchelor et al, 2010; Sato et al, 2006), was shown to cause significant increases in the intracellular PKG activation in vascular smooth muscle cells (Fiscus et al, 1983). This "basal activation" of PKG, induced by the basal, low-level (0.01 - 0.1 nanomolar) NO is now recognized to play a key role in protecting against the development of hypertension and other cardiovascular pathologies.

Advanced age (Chan \& Fiscus, 2002; Fiscus, 1988; Fiscus, 2002; Fiscus \& Ming, 2000; Fung et al, 2005) or diabetes and/or obesity in younger individuals (Fiscus, 2002; Fiscus et al, 2001; Fiscus \& Ming, 2000) results in the dysregulation of NO production and NO's ability to activate PKG in both the cardiovascular system and the male reproductive system (Chang et $a l, 2004)$. This diminished capacity to generate the physiological levels of NO and for NO to activate PKG within cells is now recognized to play a key role in aging- and diabetes/obesity-induced pathological complications, including hypertension, atherosclerosis (with increased risk of heart attack and stroke) and erectile dysfunction. 


\section{Anti-apoptotic effects mediated by the low-level-NO/cGMP/PKG- l $\alpha$ signaling pathway in neural cells, uterine epithelial cells and human ovarian cancer cells}

Further studies from our laboratory have shown that other types of mammalian cells, including uterine epithelial cells and many types of neural cells, possess all of the components of the NO/cGMP/PKG signaling pathway and that this pathway is biologically functional (Barger et al, 1995; Chan \& Fiscus, 2003; Cheng Chew et al, 2003; Fiscus, 2002; Fiscus et al, 2002; Leung et al, 2010). However, in contrast to the contractile-regulatory role of the NO/cGMP/PKG pathway identified in vascular smooth muscle cells, these other mammalian cells utilize this pathway to regulate a very different biological function, i.e. cell survival. Activation of this signaling pathway by low, basal levels of endogenous NO (generated by either eNOS or neural-form NOS (nNOS) within these cells) results in the suppression of both spontaneous apoptosis and toxin-induced apoptosis in uterine epithelial cells and in the many different types of neural cells.

We had hypothesized that, if present in ovarian cancer cells, the NO/cGMP/PKG signaling pathway may also suppress the apoptosis of tumor cells, potentially contributing to the resistance to chemotherapeutic agents (i.e. chemoresistance). Our data have shown that human ovarian cancer cells do indeed express all of the key components of the $\mathrm{NO} / \mathrm{cGMP} / \mathrm{PKG}$ signaling pathway, including all three isoforms of NOS, i.e. eNOS (also called NOS3), nNOS (also called NOS1) and inducible NOS (iNOS, also called NOS2), thus providing an endogenous source of NO (Leung et al, 2008). Furthermore, ovarian cancer cells continuously produce $\mathrm{NO}$ at low physiological levels, which tonically activates the heme-dependent soluble guanylyl cyclase (Fraser et al, 2006), elevating cGMP levels sufficiently enough to cause continuous high-level activation of PKG (Leung et al, 2010). We have found that the type-I $\alpha$ splice variant of PKG-I (i.e. PKG-I $\alpha$ ) appears to represent the predominant isoform of PKG expressed in two types of human ovarian cancer cells, OV2008 cells (possessing wild-type p53 and sensitivity to the toxic/pro-apoptotic effects of cisplatin) and A2780cp cells (possessing mutated p53 and resistance to the toxic/pro-apoptotic effects of cisplatin). The PKG-I $\alpha$ isoform is the most sensitive of all of the three isoforms of PKG (PKG-I $\alpha$, PKG-I $\beta$ and PKG -II) to stimulation by cGMP and thus is likely to be the only PKG isoform that is substantially activated by the presence of the lower physiological levels $(0.01$ -1 nanomolar) of NO (see model in Figure 1).

\section{Low-level-NO/cGMP/PKG-I $\alpha$ pathway also promotes DNA synthesis and cell proliferation, which are biological responses opposite of those induced by high-level NO}

Figure 1 illustrates the multiple (in some cases, opposite) biological effects of NO in human ovarian cancer cells, which greatly depend on the concentration [shown in nanomolar (nM)] of NO and the experimental conditions (e.g. whether there are elevated levels of superoxide, which is capable of reacting with high-level $\mathrm{NO}$ to form peroxynitrite). Most previous studies of NO's role in ovarian cancer have focused on the toxic effects of NO that occur at the higher concentrations (Cantuaria et al, 2000; Farias-Eisner et al, 1994; Garban \& Bonavida, 1999; Rieder et al, 2001), which would lead to direct S-nitrosylation of cysteine residues of proteins (Nakamura \& Lipton, 2010; Seth \& Stamler, 2011) and indirect nitration (via production of peroxynitrite) of tyrosine residues of proteins (Beckman \& Koppenol, 1996; 
Fiscus, 2002; Fiscus et al, 2002), as illustrated in Figure 1. In both cases, this can lead to cytotoxicity, with resulting inhibition of cell proliferation and induction of apoptosis.

\section{Concentration dependence of nitric oxide's biological actions in human ovarian cancer cells}

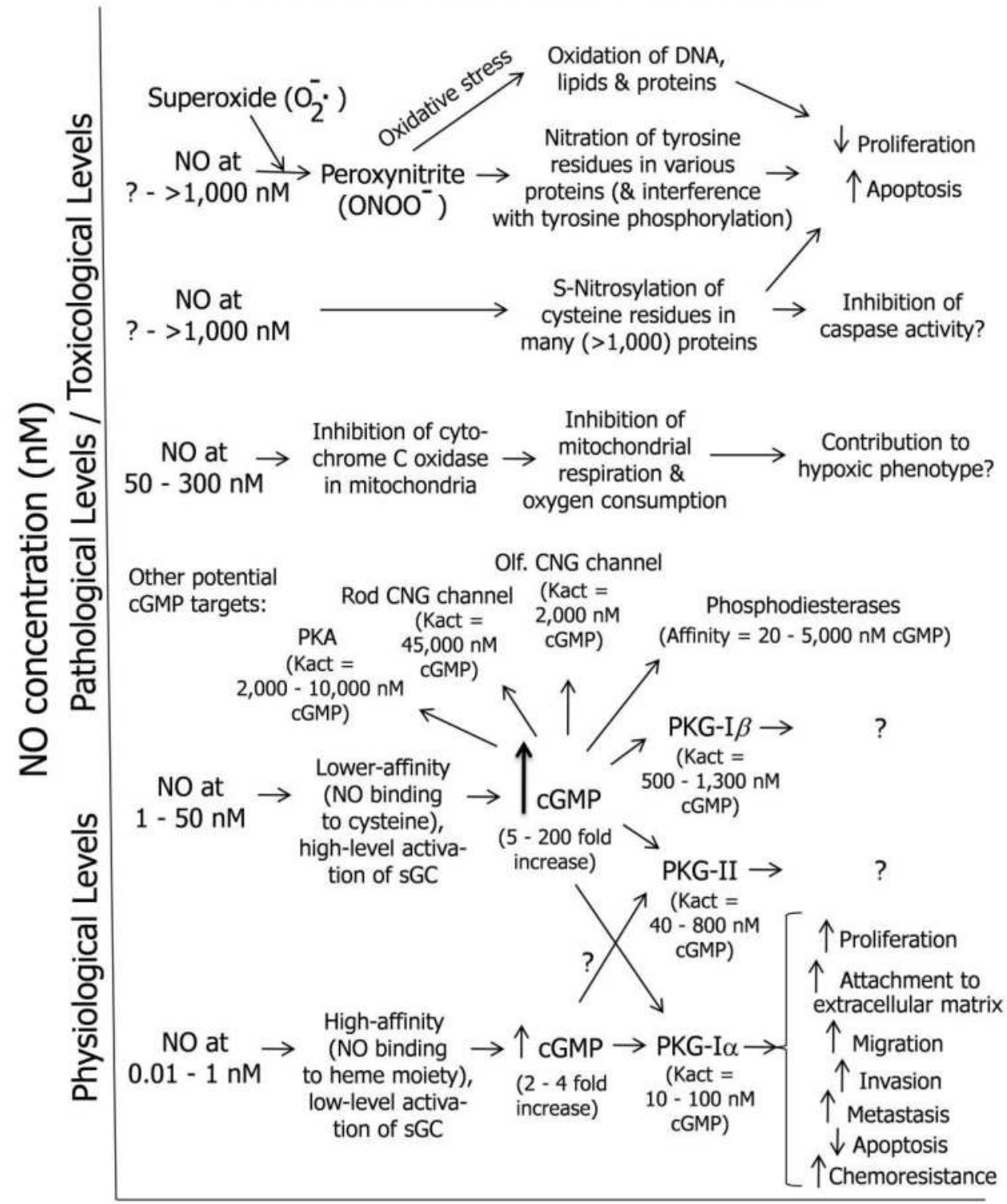

Fig. 1. Multiple cellular and molecular actions of NO in human ovarian cancer cells that occur at very different (local micro-environmental) NO concentrations [in nanomolar (nM)]. 
Figure 1 also illustrates how NO, at intermediate levels (i.e. 50 - 300 nanomolar), binds to the heme group of cytochrome $\mathrm{C}$ oxidase in the mitochondria, inhibiting the activity of this important metabolic enzyme (Bellamy et al, 2002). The biological role of this response to NO is currently unclear, but likely would result in decreased mitochondrial respiration and oxygen consumption and may possibly contribute to the hypoxic phenotype of cancer cells. At $1-50$ nanomolar concentration, which is at the transition between the toxicological levels and the higher physiological levels, NO would cause high-level activation of soluble guanylyl cyclase, causing large increases in the intracellular levels of cGMP. Recently, this high-level activation was shown to be dependent not only on the binding of NO to the heme group of soluble guanylyl cyclase (which occurs at much lower concentrations, i.e. $0.01-1$ $\mathrm{nM}$, of NO) but also on the binding of higher-level NO to cysteine residues of soluble guanylyl cyclase (Fernhoff et al, 2009). It is not clear at present what effect this would have in human ovarian cancer cells. However, studies with other types of cells have shown that larger increases in cGMP levels would activate both the PKG-I $\alpha$ and PKG-I $\beta$ isoforms of PKG, and thus may result in biological responses that are very different from those mediated by the low-level-NO/cGMP/PKG-I $\alpha$ pathway (for details, see Section 6 . below). The large increases in cGMP caused by $\mathrm{NO}$ at $1-50$ nanomolar may also regulate the activity of other potential cGMP-target proteins, including the olfactory- and rod-type CNG channels (cyclic nucleotide-gated cation channels), various phosphodiesterases and PKA (via "cross-activation" mediated by high-level cGMP binding to the cAMP-activation sites of PKA) [reviewed in (Fiscus, 2002; Francis et al, 2010; Hofmann et al, 2006; Lincoln et al, 2001; Pilz \& Casteel, 2003)].

At the lower physiological levels (0.01 - 1 nanomolar) NO would selectively activate the PKG-I $\alpha$ isoform of PKG in human ovarian cancer cells, which stimulates DNA synthesis/cell proliferation and suppresses apoptosis (promoting chemoresistance) (Leung et al, 2008; Leung et al, 2010), responses opposite to those of the high/toxic concentrations of NO. Studies in our laboratory, using both normal and malignant cells, including vascular smooth muscle cells, bone marrow-derived stromal cells and neuroblastoma cells, have suggested that a major role of the low-level-NO/cGMP/PKGI $\alpha$ signaling pathway is to protect these cells against the toxic/pro-apoptotic effects of high-level NO, as might occur during inflammation and exposure of cells to proinflammatory cytokines (Cheng Chew et al, 2003; Fiscus, 2002; Fiscus et al, 2002; Wong \& Fiscus, 2010; Wong \& Fiscus, 2011).

Recent evidence from our laboratory also suggests that the basal activation of PKG-I $\alpha$ leads to increased attachment of cells to the extracellular matrix and increased cell migration, shown in bone marrow-derived stromal cells (Wong \& Fiscus, 2011) as well as mesothelioma and non-small cell lung cancer cells (Fiscus \& Johlfs, 2011). If similar attachment and migration responses occur in ovarian cancer cells, these PKG-I $\alpha$-mediated cellular effects could lead to increased invasion and metastasis. Further experiments are currently underway to test this possibility in models of ovarian cancer.

\section{Interaction between c-Src and PKG-I $\alpha$ in promoting DNA synthesis and cell proliferation}

Studies from our laboratory suggest that the growth-promoting effect of PKG-I $\alpha$ in ovarian cancer cells involves the enhancement of the tyrosine kinase activity of c-Src (Leung et al, 
2010), an oncogenic protein often overexpressed and/or hyperactivated in many types of cancer cells, including ovarian cancer cells. The key role of PKG-I $\alpha$ in activating c-Src and promoting cell proliferation was determined using siRNA gene knockdown techniques, which specifically silences the gene expression of PKG-I $\alpha$, and two types of pharmacological inhibitors, ODQ (1H-[1,2,4] oxadiazolo[4,3-a]quinozalin-1-one, an inhibitor of endogenous NO-induced, heme-dependent activation of soluble guanylyl cyclase) and DT-2 or DT-3 (two highly-specific inhibitors of the serine/threonine kinase activity of PKG-I $\alpha$ ) (Leung et al, 2010).

Epidermal growth factor (EGF)-induced activation of c-Src tyrosine kinase activity was found to cause tyrosine phosphorylation of PKG-I $\alpha$, increasing the serine/threonine kinase activity of PKG-I $\alpha$ and its growth-promoting effects in ovarian cancer cells (Leung et al, 2010). Furthermore, we have found that PKG-I $\alpha$ directly phosphorylates c-Src at serine-17, which enhances the tyrosine kinase activity of c-Src in both in vitro and intact-cell experiments (Fiscus \& Johlfs, 2011). In human ovarian cancer cells, the c-Src-mediated tyrosine-phosphorylation of the EGF receptor was found to be highly dependent on PKG-I $\alpha$ kinase activity (Leung et al, 2010). Thus, there appears to be a novel interaction between PKG-I $\alpha$ and c-Src in human ovarian cancer cells. This interaction causes reciprocal phosphorylation, i.e. each protein kinase phosphorylating the other, potentially setting up an "oncogenic reinforcement" resulting in exaggerated DNA synthesis and cell proliferation.

\section{Opposite effects of the two PKG-I splice variants, PKG-I $\alpha$ and PKG-I $\beta$, on cell proliferation and apoptosis}

Our studies of mammalian cells expressing both PKG-I $\alpha$ and PKG-I $\beta$ isoforms, such as vascular smooth muscle cells, show that exposure of these cells to NO in a wide concentration range results in biphasic responses of cell proliferation and apoptosis (Wong \& Fiscus, 2010). For example, exposure to low physiological levels of NO tends to promote cell proliferation and suppress apoptosis (i.e. promote cytoprotection), whereas exposure to higher levels of NO has the opposite effects, suppressing cell proliferation and promoting apoptosis. Similar biphasic responses to different concentrations of NO have been reported in vascular endothelial cells (Isenberg et al, 2005). These opposite effects induced by the low and high levels of NO likely involve the many cellular and molecular mechanisms illustrated in the model of Figure 1. Of particular interest in our laboratory is the role played by the two splice variants of PKG-I, since both isozymes are expressed in vascular smooth muscle cells (Wong \& Fiscus, 2010). At low levels, NO would selectively stimulate the kinase activity of PKG-I $\alpha$ (but not PKG-I $\beta$ ), because the PKG-I $\alpha$ isoform has a much higher sensitivity to NO and the cGMP-induced allosteric activation (illustrated in Figure 2). At higher levels, NO would activate both PKG-I isoforms. Importantly, PKG-I $\beta$ requires at least 10-times higher levels of cGMP for activation (indicated by $\mathrm{K}_{\mathrm{act}}$ ), compared with PKG-I $\alpha$ (Francis et al, 2010; Hofmann et al, 2006; Lincoln et al, 2001; Pilz \& Casteel, 2003). Activation of PKG-I $\beta$ by the high-level NO likely contributes to suppression of cell proliferation and induction of apoptosis [(Wong \& Fiscus, 2010) and illustrated in Figure 2]. 


\section{Opposite effects of the two PKG-I splice variants on apoptosis and proliferation}

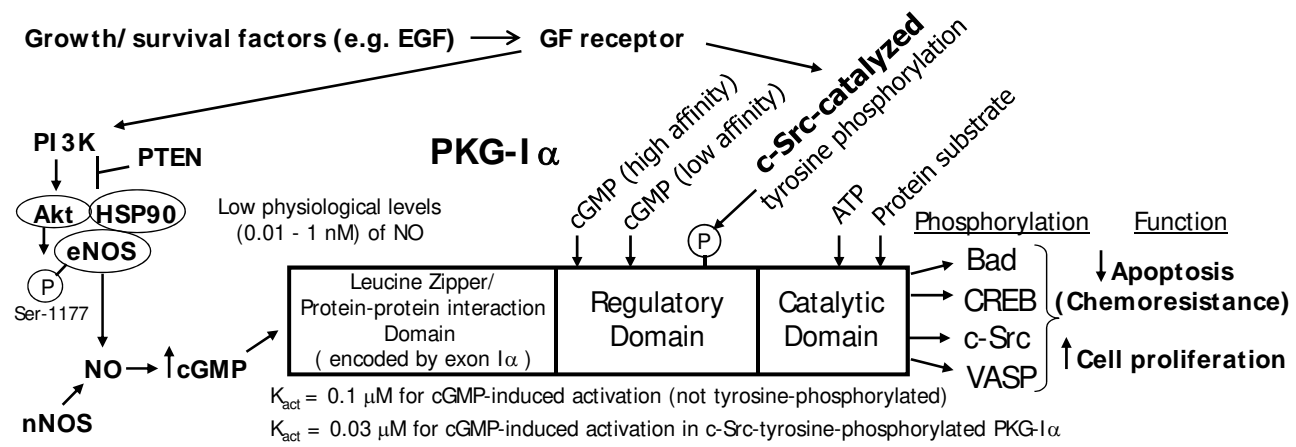

R.R. Fiscus' lab: Human ovarian cancer cells

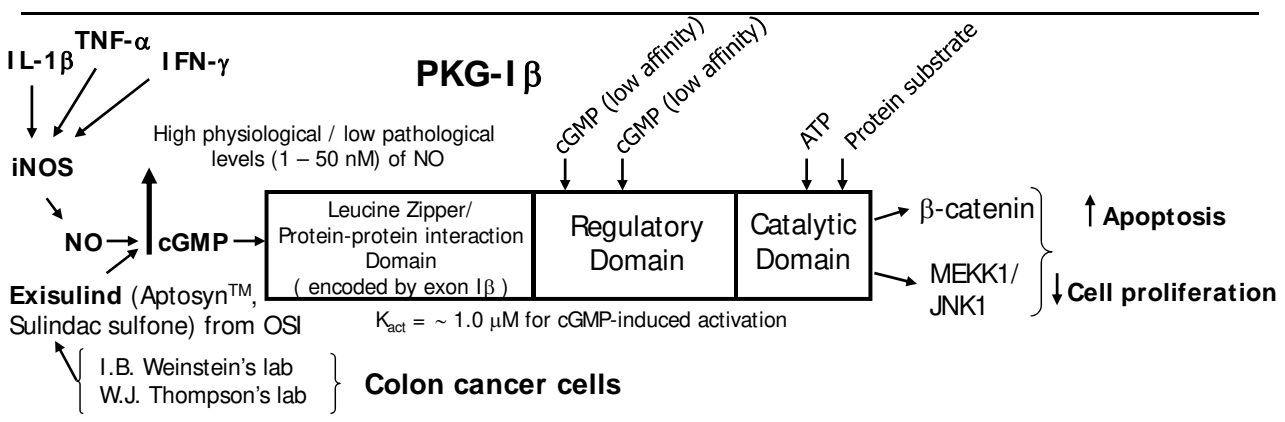

Fig. 2. Model of the two splice variants of PKG-I, illustrating their activation by different concentration ranges of $\mathrm{NO}$ and the downstream phosphorylation of different sets of target proteins. Also, the model for PKG-I $\alpha$ illustrates the effects of growth factors (e.g. EGF), which stimulates both the PI3K/Akt pathway, enhancing eNOS activity and low-level NO generation, and c-Src activation, catalyzing downstream tyrosine-phosphorylation of PKG$\mathrm{I} \alpha$, enhancing its sensitivity to allosteric activation by cGMP (represented by the $\mathrm{K}_{\text {act }}$ values).

In human ovarian cancer cells, we found that endogenous PKG-I $\alpha$ is tyrosinephosphorylated, which depends on the high-level tyrosine kinase activity of c-Src (Leung et $a l, 2010)$. The tyrosine phosphorylation of PKG-I $\alpha$ is known to cause a 3-fold decrease in the $\mathrm{K}_{\mathrm{act}}$ for cGMP-induced activation, resulting in a substantial sensitization of the PKG-I $\alpha$ to its activation by cGMP (illustrated in Figure 2). Earlier in vitro experiments, using purified PKG-I $\alpha$ in a kinase reaction mixture with v-Src, the viral form of Src, had shown that tyrosine-phosphorylation of PKG-I $\alpha$ results in a 3-fold shift downwards in the $\mathrm{K}_{\text {act }}$ (LaFevreBernt et al, 1998). The human form of c-Src, used in our studies, has the same catalytic domain as v-Src and thus catalyzes the same type of tyrosine-phosphorylation of PKG-I $\alpha$ (Leung et al, 2010). Thus, in human ovarian cancer cells the tyrosine-phosphorylated PKG-I $\alpha$ would be dramatically sensitized to the activation by basal intracellular cGMP levels, resulting in high-level activation (i.e. hyperactivation, estimated to be $\sim 90 \%$ of maximal activity) of PKG-I $\alpha$ within the ovarian cancer cells.

Our laboratory has shown that activation of PKG-I $\alpha$, which occurs tonically in cells that express either eNOS or nNOS, results in stimulation of DNA synthesis/cell proliferation 
and suppression of apoptosis in a variety of mammalian cells, notably human ovarian cancer cells (Fiscus, 2002; Fiscus et al, 2002; Fraser et al, 2006; Leung et al, 2008; Leung et al, 2010; Wong \& Fiscus, 2010; Wong \& Fiscus, 2011). In contrast, activation of both isoforms of PKG-I, following the exposure to higher-level NO in cells expressing both PKG-I isoforms, results in suppression of DNA synthesis/cell proliferation and induction of apoptosis (Wong \& Fiscus, 2010). It appears that when PKG-I $\beta$ is activated by the higher levels of NO, the growth-inhibitory and pro-apoptotic effects of PKG-I $\beta$ predominate over the growthstimulatory and anti-apoptotic effects mediated by PKG-I $\alpha$. Because of these differences in the biological responses mediated by the two isoforms of PKG-I and because most previous studies have used higher levels of NO, there has been confusion in the literature about the role of PKG in regulating cell proliferation and apoptosis.

Figure 2 illustrates the opposite biological effects of PKG-I $\alpha$ and PKG-I $\beta$ on cell proliferation and apoptosis, using, as examples, two types of cells that selectively express one isoform of PKG-I or the other. As stated above, our studies have shown that human ovarian cancer cells appear to express predominantly the PKG-I $\alpha$ isoform, and that the activation of this kinase by endogenous low-level NO generated by eNOS and nNOS within ovarain cancer cells promotes DNA synthesis/cell proliferation and suppresses apoptosis, contributing to chemoresistance (i.e. interfering with the toxic/cancer-cell-killing effects of cisplatin) (Leung et al, 2008; Leung et al, 2010), shown in the upper model of Figure 2. The lower model in Figure 2 shows the regulation and downstream target proteins of PKG-I $\beta$, based in part on published data from the laboratories of I.B. Weinstein and W.J. Thompson. Their laboratories have shown that PKG-I $\beta$ is the predominant isoform of PKG-I expressed in colon cancer cells and that, when activated [following the large increases in intracellular cGMP levels induced by Exisulind, a type-2/type-5 phosphodiesterase (PDE2/PDE5) inhibitor], PKG-I $\beta$ phosphorylates two downstream target proteins, $\beta$-catenin and MEKK1, resulting in inhibition of cell proliferation and induction of apoptosis (Deguchi et al, 2004; Soh et al, 2000; Thompson et al, 2000). They also showed that the overexpression of PKG-I $\beta$ in colon cancer cells causes a large suppression of cell proliferation and induction of apoptosis. Although their studies further showed that transfection of colon cancer cells with vectors causing overexpression of PKG-I $\alpha$ also caused a small inhibition of cell proliferation, it appears likely that this forced overexpression of PKG-I $\alpha$ may have resulted in the unnatural exposure of PKG-I $\alpha$ to target proteins that normally would not be phosphorylated by naturally-expressed PKG-I $\alpha$ (but rather by PKG-I $\beta$ ), leading to biological responses more like those of the PKG-I $\beta$ isoform. Overall, the combined data from our laboratory using human ovarian cancer cells and the data from the laboratories of I.B. Weinstein and W.J. Thompson using colon cancer cells suggest that the two isoforms of PKG-I have opposite effects on cell proliferation and apoptosis. However, further studies will be needed to determine if cell-type differences may have also played a role in the opposite biological responses mediated by the two PKG-I isoforms.

In the model of PKG-I $\beta$ shown in Figure 2, we have also included our current concept about the natural endogenous activator of PKG-I $\beta$ within cancer cells, which we believe likely involves high-level NO generated by iNOS, either within the cancer cells themselves or within invading white blood cells (e.g. monocyte/macrophages), following their exposure to pro-inflammatory cytokines, such as interleukin-1 $\beta$ (IL-1 $\beta$ ), tumor necrosis factor- $\alpha$ (TNF$\alpha)$ and interferon- $\gamma($ IFN- $\gamma$ ). These pro-inflammatory cytokines are known to induce the gene expression of iNOS (Chan \& Fiscus, 2004; Kleinert et al, 2003), which causes high-level 
production of NO and large increases in the intracellular levels of cGMP. Thus, the role of PKG-I $\beta$ in regulating cell proliferation and apoptosis in cancer cells will depend on whether or not the cells actually express this isoform of PKG and whether or not there are concurrent inflammatory conditions in the tumor that would lead to the induction of iNOS and high levels of NO and cGMP, needed for activating PKG-I $\beta$.

Figure 2 further shows the difference between PKG-I $\alpha$ and PKG-I $\beta$ in terms of the immediate downstream target proteins that are being phosphorylated by the two protein kinases. Earlier studies had shown that PKG-I $\alpha$ and PKG-I $\beta$ have identical substrate specificities when tested in in vitro experiments (Francis et al, 2010; Hofmann et al, 2006; Lincoln et al, 2001), which used freely soluble kinases (either purified kinases or recombinant kinases) dissolved in an aqueous solution. The two isoforms of PKG-I have identical catalytic domains, which results in similar substrate specificity when tested in vitro. However, within intact cells, PKG-I $\alpha$ and PKG-I $\beta$ have very different subcellular localizations, because of their different localization domains (i.e. the leucine zipper/proteinprotein-interaction domains), which represents the first 100 amino acids at the N-terminal encoded by the different first exons of the two splice variants of PKG-I. This difference in the subcellular localizations results in the exposure of the two PKG-I isoforms to very different sets of downstream target proteins, as illustrated in Figure 2.

Our studies have suggested that there is continuous high-level activation of PKG-I $\alpha$ within cancer cells, which results in continuous downstream phosphorylation of four key regulatory proteins: 1) the apoptosis-regulating protein Bad (Johlfs \& Fiscus, 2010), 2) the transcription factor CREB [(Fiscus, 2002), further supported by recent data from our laboratory using many types of cancer cells], 3) the oncogenic tyrosine kinase c-Src (Fiscus \& Johlfs, 2011; Leung et al, 2010), and 4) the actin-filament- and focal-adhesion-associated protein VASP (vasodilator-stimulated phosphoprotein) (Leung et al, 2010; Wong \& Fiscus, 2010; Wong \& Fiscus, 2011). We have proposed that the PKG-I $\alpha$-mediated phosphorylations of Bad, CREB, c-Src and VASP play important roles in promoting chemoresistance, DNA synthesis/cell proliferation, cell attachment and cell migration. Others have shown that PKG-I $\beta$ phosphorylates $\beta$-catenin and MEKK1 in colon cancer cells, which ultimately leads to increased levels of apoptosis and inhibition of cell proliferation in the colon cancer cells (Deguchi et al, 2004; Soh et al, 2000; Thompson et al, 2000).

\section{Identification of PKG-I $\alpha$ as the exclusive isoform of PKG-I expressed in A2780cp and OV2008 human ovarian cancer cells using the NanoPro100 system, a new ultrasensitive immuno-detection instrument based on capillary electrophoresis}

Although our previous studies using Western blot analysis had suggested that PKG-I $\alpha$ is the predominant isoform of PKG-I expressed in A2780cp and OV2008 human ovarian cancer cells (Leung et al, 2010), we had found it difficult to determine the PKG-I isozyme profile with certainty because of the relatively low abundance of the PKG-I isoforms in cancer cells and the difficulty in resolving and identifying the two isoforms of PKG-I using Western blot analysis. Other laboratories, also using Western blot analysis, were unable to detect PKG expression in ovarian cancer cells and various other types of cancer cells, which had lead them to conclude that "PKG expression is lost" in cancer cells (Hou et al, 2006; Wong et al, 2001). Our studies have now shown that all of the more than 25 different cancer cell lines 
tested in our laboratory, including breast cancer, colon cancer, lung cancer, melanoma, mesothelioma, ovarian cancer and prostate cancer cells, do indeed express PKG-I isoforms, with PKG-I $\alpha$ expressed in all cell lines and PKG-I $\beta$ co-expressed in about half of them. The misunderstanding about whether or not cancer cells actually express PKG-I isoforms had resulted from of the lack of sensitivity of conventional Western blot analysis (and the lack of sensitivity of conventional immunohistochemistry), resulting in the inability to detect the protein expression of the PKG-I isoforms. To avoid this technical problem caused by the inadequate sensitivity of conventional Western blot analysis, our laboratory has begun using a new, state-of-the-art methodology that utilizes the NanoPro100 system, a capillaryelectrophoresis-based immuno-detection instrument, manufactured and marketed by ProteinSimple (previously named Cell Biosciences, Inc.), Santa Clara, CA, USA. The NanoPro100 system allows protein detection with a sensitivity that is $>100$-times better than conventional Western blot analysis, thus allowing clear identification of lower abundance proteins that have escaped detection by Western blot analysis. Furthermore, the NanoPro100 system is able to cleanly separate the two isoforms of PKG-I, thus making it much easier to identify which isoforms are expressed in cancer cells.

Figure 3 shows the dramatic improvement in sensitivity and resolving power of the NanoPro100 system for determining the PKG-I isoform expression profiles in human ovarian cancer cells, compared with conventional Western blot analysis (panel A). Recombinant PKG-I $\alpha$ and PKG-I $\beta$ were used as standards in the NanoPro100 system (panel B). The NCI-H2052 mesothelioma cell line, which expresses both isoforms of PKG-I, was used as a positive control, illustrating the correct positions for the two PKG-I isoforms in the NanoPro100 electropherograms following analysis of cell lysates (panel C). Both A2780cp and OV2008 human ovarian cancer cells were found to express exclusively the PKG-I $\alpha$ isoform (panels D and E), thus confirming our earlier report using conventional Western blot analysis. Interestingly, because the NanoPro100 system separates proteins based on pI rather than molecular weight as in conventional Western blot analysis, this new state-of-theart technology is able to separate and potentially identify the different phosphorylated forms (phospho-forms) of proteins, illustrated by the additional peaks to the left side of the main peak for PKG-I $\alpha$ in panels D and E of Figure 3. The identification of these additional peaks as being phospho-forms of PKG-I $\alpha$ is shown by their decrease after treatment of the cell lysates with lambda phosphatase, which removes the phosphate groups.

Based on the NanoPro100 data of Figure 3, the chemoresistant A2780cp cell line appears to have lower expression levels of PKG-I $\alpha$ compared with the chemosensitive OV2008 cell line. On the surface, this seems to be opposite to what would be expected if PKG-I $\alpha$ is contributing to chemoresistance in human ovarian cancer cells. However, it should be emphasized that protein expression levels do not indicate the functional activity of protein kinases. Much more important in determining the actual functional activity within cells are the levels of phosphorylation at regulatory sites (e.g. c-Src-mediate phosphorylation of tyrosine residues, in the case of PKG-I $\alpha$ ) and the intracellular concentrations of allosteric activators (e.g. cGMP, in the case of PKG-I $\alpha$ ). Another important determinant for functional kinase activity within cells is the subcellular localization, which determines the efficiency of phosphorylation and which of the potential downstream target proteins are actually phosphorylated (as illustrated in Figure 2 and discussed in Section 6.). Thus, the protein expression levels (of the total protein), as measured by Western blot analysis or NanoPro100 analysis, cannot directly predict the functional kinase activity of a protein kinase. 
A. PKG-I $\alpha / \beta$ protein expression analysis by traditional Western blot

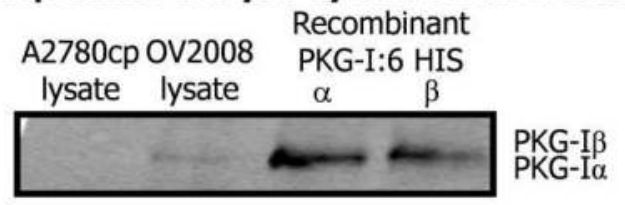

\section{B. Recombinant PKG-I $\alpha / \beta$ detected using the NanoPro100 system}
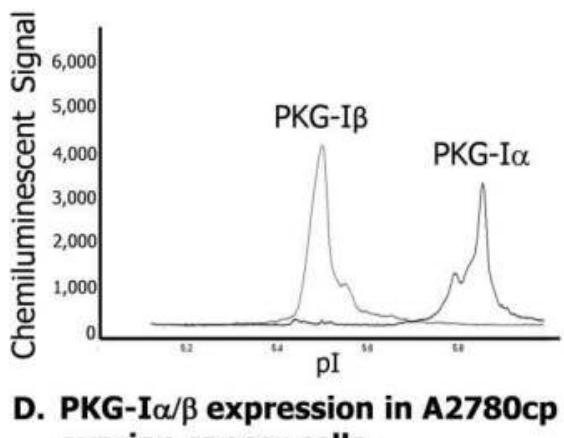
ovarian cancer cells
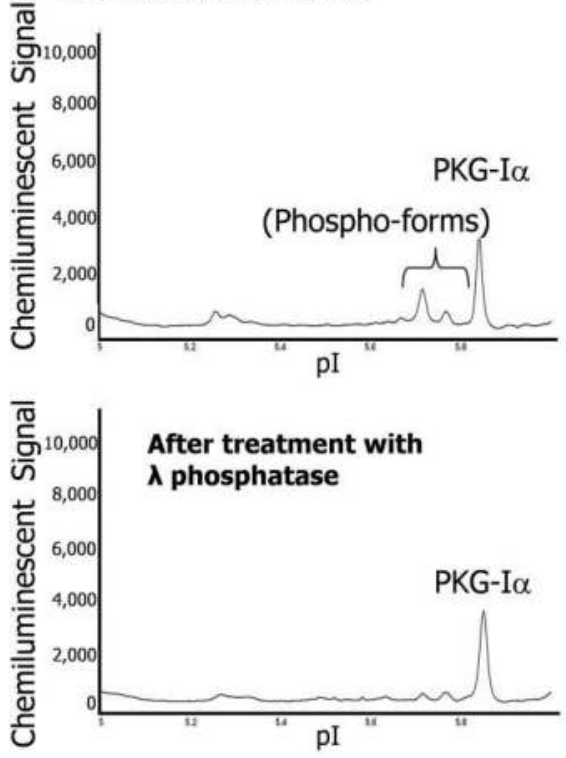

\section{PKG-I $\alpha / \beta$ expression in NCI- H2052 mesothelioma cells}

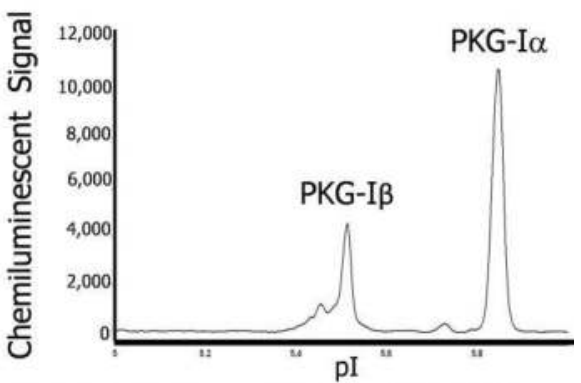

\section{E. PKG-I $\alpha / \beta$ expression in OV2008 ovarian cancer cells}
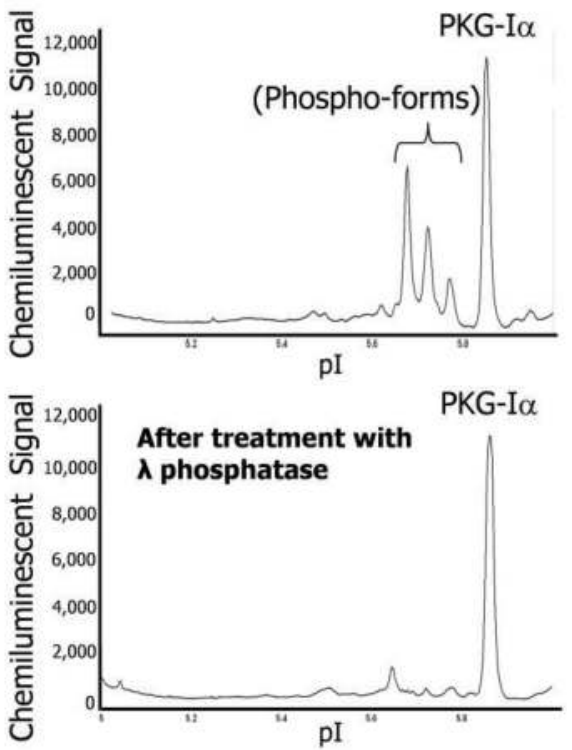

Fig. 3. Comparison between traditional Western blot analysis and the new ultrasensitive Nanopro100 system for identifying two PKG-I isoforms expressed in human ovarian cancer cell lysates. A. Western blot analysis of $1.56 \mu \mathrm{g}$ total cellular protein in cell lysates of A2780cp and OV2008 cells. B - E. NanoPro100 analysis using 3.13 ng of total cellular protein in cell lysates. The lower electropherograms in D. \& E. represent cell lysates treated for 30 minutes at $37^{\circ} \mathrm{C}$ with lambda phosphatase to remove phosphate groups from the proteins. 
In many of our previous studies, there appears to be an inverse relationship between the protein expression levels and the kinase activity of PKG-I $\alpha$. For example, vascular smooth muscle cells have exceptionally high levels of PKG-I $\alpha$ protein expression but relatively low levels of PKG-I $\alpha$ kinase activation (e.g. 30\% - 40\% of maximal activity) (Fiscus, 1988; Fiscus \& Murad, 1988; Fiscus et al, 1983). In contrast, many cancer cells, including human ovarian cancer cells, have relatively low levels of PKG-I $\alpha$ protein expression but high levels of PKGI $\alpha$ kinase activation (i.e. hyperactivation, estimated to be $\sim 90 \%$ of maximum activity) (Johlfs \& Fiscus, 2010; Leung et al, 2010). We have proposed that the reason for this inverse relationship between protein expression levels and kinase activation levels is because of a negative-feedback mechanism, in which increases in PKG-I $\alpha$ kinase activity (as, for example, resulting from c-Src-mediated tyrosine phosphorylation of PKG-I $\alpha$ in cancer cells) would result in the negative modulation of PKG-I $\alpha$ gene expression and protein expression, ultimately leading to the relatively low protein levels of PKG-I $\alpha$. However, in spite of lower protein levels (as measured in a Western blot analysis), the actual functional activity of PKG-I $\alpha$ may remain quite high because of more-targeted subcellular localization, efficiently placing PKG-I $\alpha$ in contact with its downstream target proteins. We have proposed that this may be the explanation for the low protein levels and high kinase activity of PKG-I $\alpha$ in cancer cells, especially those overexpressing or having hyperactivated c-Src.

Negative feedback regulations of PKG-I $\alpha$ expression at both the messenger RNA and protein levels have been shown in studies by Thomas Lincoln's laboratory at the University of South Alabama (Dey et al, 2009; Lincoln et al, 2001). Exposure of vascular smooth muscle cells to high levels of NO, causing large increases in intracellular cGMP levels, or to cellpermeable cGMP analogs that hyperactivate PKG-I $\alpha$, causes (negative-feedback) downregulation of PKG-I $\alpha$ gene expression (Lincoln et al, 2001). Furthermore, high-level activation of PKG-I $\alpha$ also results in the ubiquitination of PKG-I $\alpha$ and its degradation by the proteasome (Dey et al, 2009). If such mechanisms are involved in regulating the protein expression levels of PKG-I $\alpha$ in cancer cells, then the lower levels of protein expression of PKG-I $\alpha$, as was found in the chemoresistant A2780cp ovarian cancer cells (Figure 3), may actually reflect a higher level of functional PKG-I $\alpha$ kinase activity. Future experiments will test this possibility.

\section{Overall model of the involvement of the NO/cGMP/PKG-la signaling pathway in promoting tumor growth, chemoresistance and angiogenesis in ovarian cancer}

Figure 4 illustrates our overall model showing the involvement of the NO/cGMP/PKG-I $\alpha$ pathway in promoting cell proliferation and suppressing apoptosis in human ovarian cancer cells, which would contribute to enhanced tumor growth and chemoresistance. Also shown in the model is the potential role of nearby endothelial cells, which would provide an additional source of endogenous NO within the growing tumor, potentially contributing to the "angiogenic switch", i.e. the increased tumor growth that occurs after the invasion of endothelial cells into the tumor. Many factors are released from the endothelial cells that can stimulate the growth and chemoresistance of the tumor. Because low physiological levels $(0.01-1 \mathrm{nM})$ of NO are now recognized to play a key role in promoting cancer cell proliferation and the development of chemoresistance, the NO released from nearby endothelial cells may have an important role in the tumor growth and chemoresistance 
commonly found in ovarian cancer. Endothelial cells also play another important role in tumor growth by providing new blood vessels (i.e. angiogenesis) needed for the vascularization and blood perfusion of the growing tumor.

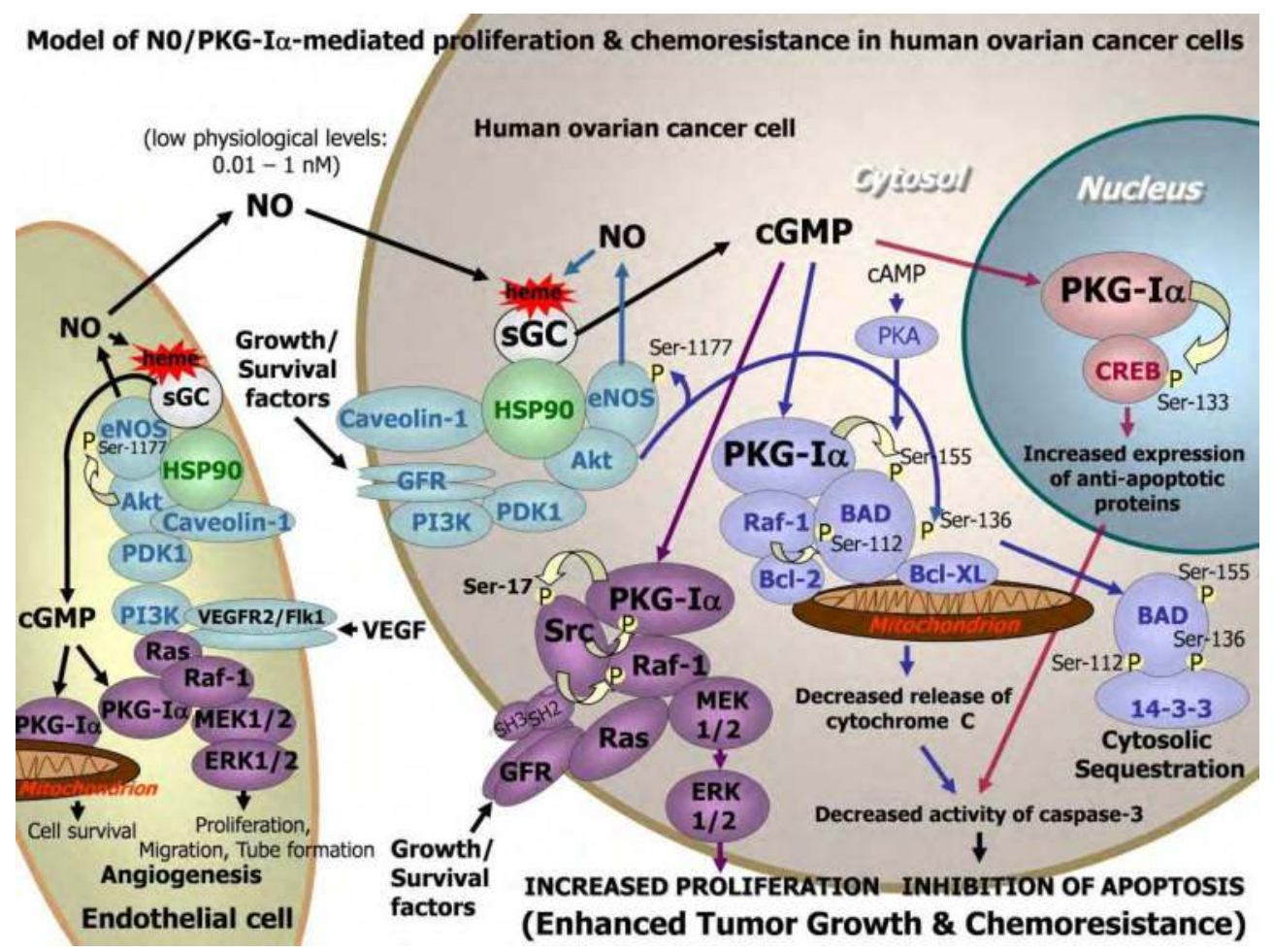

Fig. 4. Cellular model of the involvement of the NO/cGMP/PKG-I $\alpha$ signaling pathway in promoting chemoresistance, tumor growth and angiogenesis in ovarian cancer.

Angiogenesis, especially that stimulated by VEGF (vascular endothelial growth factor), is now recognized to involve the stimulation of NO synthesis by eNOS within endothelial cells, which results in PKG activation and PKG-mediated downstream stimulation of MEK and ERK [reviewed in (Pilz \& Casteel, 2003)]. This activation of the ERK signaling pathway is thought to result in enhanced proliferation, migration and tube formation of endothelial cells, key components of angiogenesis, all dependent on the NO/cGMP/PKG pathway. Although it has not yet been reported which isoform of PKG is involved in the multiple proangiogenesis responses of endothelial cells, our recent studies suggest that endothelial cells express predominantly the PKG-I $\alpha$ isoform (unpublished observations by J.C. Wong and R.R. Fiscus), which likely mediates the stimulation of downstream growth-promoting and pro-angiogenesis pathways in endothelial cells.

Figure 4 illustrates the interaction between PKG-I $\alpha$ and c-Src, which results in the reciprocal phosphorylation, i.e. each kinase phosphorylating the other. Our studies have shown that activation of EGF receptors in human ovarian cancer cells causes downstream activation of c-Src, which is completely dependent on the kinase activity of PKG-I $\alpha$ (Leung et al., 2010). 
At the time, it was not completely clear how PKG-I $\alpha$ was able to promote the activation of cSrc by EGF, but we had hypothesized that PKG-I $\alpha$ may be able to catalyze the phosphorylation of a serine or threonine residence of c-Src that was important for enhancing c-Src's tyrosine kinase activity. Upon reviewing the amino acid sequence of c-Src, we recognized that serine-17 could possibly serve as a phosphorylation site for PKG-I $\alpha$, based on the surrounding amino acids that provided a good consensus sequence for PKG-I $\alpha-$ catalyzed phosphorylation. To test this idea, we have worked with Cell Signaling Technologies (Danvers, MA, USA) over the last three years to develop an antibody that specifically recognizes the phosphorylated-form of serine-17 in c-Src. Using this antibody, we have shown that recombinant human-form PKG-I $\alpha$ directly phosphorylates the serine-17 site in recombinant human-form c-Src, resulting in enhanced tyrosine kinase activity of c-Src (Fiscus \& Johlfs, 2011). Using intact-cell experiments, involving two mesothelioma cell lines and a non-small cell lung cancer (NSCLC) cell line, we have further shown that gene knockdown of PKG-I $\alpha$ expression (using siRNA and shRNA) or pharmacological inhibition of PKG-I $\alpha$ activation resulted in dramatically suppressed levels of c-Src phosphorylation at serine-17, which corresponded to the inhibition of cell proliferation, increased levels of apoptosis and decreased attachment of the cells to the extracellular matrix (Fiscus \& Johlfs, 2011). These recent studies have shown a clear role of the PKG-I $\alpha$-mediated phosphorylation of c-Src at serine-17 in preventing apoptosis and promoting proliferation, attachment and migration in the mesothelioma and NSCLC cells. It is very likely that a similar PKG-I $\alpha$-catalyzed phosphorylation of c-Src at serine-17 occurs in human ovarian cancer cells, which can explain the dependence of the c-Src activation by EGF on the presence of PKG-I $\alpha$, contributing to the stimulation of ovarian cancer cell proliferation, as reported in our earlier study (Leung et al, 2010).

Also shown in the model of Figure 4 is the interaction of PKG-I $\alpha$ with two other downstream target proteins, Bad (shown in the model as BAD) and CREB. Previous studies from our laboratory and other laboratories have shown that the nuclear transcription factor CREB can be directly phosphorylated at its serine-133 site by PKG, which results in increased transcriptional activity and downstream regulation of gene expression [reviewed in (Fiscus, 2002; Pilz \& Casteel, 2003)]. Also, we have recently shown that PKG-I $\alpha$ directly phosphorylates BAD at serine-155, using in vitro experiments, and have further shown that a large part of the serine-155 phosphorylation of BAD within neuroblastoma cells is dependent on endogenous PKG-I $\alpha$ kinase activity (Johlfs \& Fiscus, 2010). Thus, BAD and CREB may be important downstream target proteins mediating the anti-apoptotic and prochemoresistant effects of the NO/cGMP/PKG-I $\alpha$ pathway in human ovarian cancer cells.

\section{Future research}

Future studies will need to determine: 1) if PKG-I $\alpha$ is the only isoform of PKG expressed in other human ovarian cancer cell lines as well as in tumor samples of patients with ovarian cancer, as we have shown for the A2780cp and OV2008 cell lines described herein and shown in Figure 3, or if there is a co-expression of the PKG-I $\beta$ isoform in some ovarian cancer cells, like in the NCI-H2052 mesothelioma cell line (Figure 3), 2) what is the subcellular localization (e.g. plasma membrane, mitochondrial, nuclear, and/or cytosolic localization) of PKG-I $\alpha$ (and possibly PKG-I $\beta$ in some ovarian cancer cells) and how this determines which downstream target proteins are phosphorylated by the different PKG 
isoforms, 3) if the NO/cGMP/PKG-I $\alpha$ signaling pathway is involved in promoting cell invasion and metastasis of ovarian cancer cells, 4) if there are other downstream target proteins that contribute to mediating the stimulation of DNA synthesis/cell proliferation, chemoresistance and metastasis of ovarian cancer cells, and 5) if the low-levelNO/cGMP/PKG-I $\alpha$ and the higher-level-NO/cGMP/PKG-I $\beta$ signaling pathways are involved in regulating apoptosis, proliferation and differentiation in the subset of ovarian cancer cells known as the ovarian tumor-initiating cells (or ovarian cancer stem cells) that may contribute to the tumorigenesis in ovarian cancer.

Our future studies will utilize the new ultrasensitive NanoPro100 system to determine the expression levels of PKG isoforms in human ovarian cancer cells. Because the NanoPro100 system separates proteins based on $\mathrm{pI}$, rather than molecular weight as in conventional Western blot analysis, the new instrument can cleanly resolve the different phosphorylated forms of proteins, as shown in Figure 3. We will use this capability to identify the different phosphorylated forms of the PKG-I isoforms as well as the downstream phosphorylation of the different target proteins of the PKG isoforms.

\section{Conclusions}

Our studies suggest that the NO/cGMP/PKG-I $\alpha$ signaling pathway and its interaction with the c-Src tyrosine kinase pathway play an essential role in promoting cell proliferation and chemoresistance in human ovarian cancer cells. The interaction with c-Src involves a novel reciprocal phosphorylation mechanism, which includes c-Src mediating the tyrosinephosphorylation of PKG-I $\alpha$, enhancing PKG-I $\alpha$ 's serine/threonine kinase activity, and PKGI $\alpha$ mediating the serine-phosphorylation of c-Src (at serine-17), enhancing c-Src's tyrosine kinase activity. We propose that this novel interaction results in an "oncogenic reinforcement" in human ovarian cancer cells, leading to the exaggerated cell proliferation and chemoresistance, illustrated in the model in Figure 4.

This new understanding of the NO/cGMP/PKG-I $\alpha$ pathway and its interaction with c-Src in human ovarian cancer cells provides new molecular targets that can be used for developing novel anti-cancer therapeutic agents. However, because NO has multiple cellular and molecular actions, illustrated in Figure 1, and the two PKG-I isoforms mediate very different biological effects, illustrated in Figure 2, future studies will need to recognize these complexities and their importance in development of new therapies for ovarian cancer.

New state-of-the-art instruments, like the NanoPro100 system, which provides $>100$-times higher sensitivity and much better specificity in identifying and quantifying protein expression and site-specific protein phosphorylation, compared with conventional Western blot analysis, will greatly facilitate our future studies. It is anticipated that the new information that will be learned about the low-level-NO/cGMP/PKG-I $\alpha$ signaling pathway and its interaction with the c-Src tyrosine kinase pathway in human ovarian cancer cells will ultimately lead to new therapies that can successfully treat ovarian cancer.

\section{Acknowledgements}

Financial support for the research involving the NanoPro100 instrument and the preparation of this book chapter was provided by Start-up Funding from Roseman University of Health Sciences (formerly named University of Southern Nevada), Henderson, 
Nevada, USA. Other parts of our research reported herein were conducted at the Nevada Cancer Institute, Las Vegas, Nevada, USA, and were supported by a grant from the U.S. Department of Defense (Grant \# W81XWH-07-1-0543) and Start-up Funding from the Nevada Cancer Institute, Las Vegas, Nevada, USA, awarded to Dr. Fiscus.

\section{References}

Barger SW, Fiscus RR, Ruth P, Hofmann F, Mattson MP (1995) Role of cyclic GMP in the regulation of neuronal calcium and survival by secreted forms of beta-amyloid precursor. J Neurochem 64(5): 2087-96.

Batchelor AM, Bartus K, Reynell C, Constantinou S, Halvey EJ, Held KF, Dostmann WR, Vernon J, Garthwaite J (2010) Exquisite sensitivity to subsecond, picomolar nitric oxide transients conferred on cells by guanylyl cyclase-coupled receptors. Proc Natl Acad Sci U S A 107(51): 22060-5.

Beckman JS, Koppenol WH (1996) Nitric oxide, superoxide, and peroxynitrite: the good, the bad, and the ugly. Am J Physiol 271(5 Pt 1): C1424-37.

Bellamy TC, Griffiths C, Garthwaite J (2002) Differential sensitivity of guanylyl cyclase and mitochondrial respiration to nitric oxide measured using clamped concentrations. J Biol Chem 277(35): 31801-7.

Cantuaria G, Magalhaes A, Angioli R, Mendez L, Mirhashemi R, Wang J, Wang P, Penalver M, Averette H, Braunschweiger P (2000) Antitumor activity of a novel glyco-nitric oxide conjugate in ovarian carcinoma. Cancer 88(2): 381-8.

Chan GH, Fiscus RR (2002) Severe impairment of CGRP-induced hypotension in vivo and vasorelaxation in vitro in elderly rats. Eur J Pharmacol 434(3): 133-9.

Chan GH, Fiscus RR (2004) Exaggerated production of nitric oxide (NO) and increases in inducible NO-synthase mRNA levels induced by the pro-inflammatory cytokine interleukin-1beta in vascular smooth muscle cells of elderly rats. Exp Gerontol 39(3): 387-94.

Chan SL, Fiscus RR (2003) Guanylyl cyclase inhibitors NS2028 and ODQ and protein kinase G (PKG) inhibitor KT5823 trigger apoptotic DNA fragmentation in immortalized uterine epithelial cells: anti-apoptotic effects of basal cGMP/PKG. Mol Hum Reprod 9(12): 775-83.

Chang S, Hypolite JA, Velez M, Changolkar A, Wein AJ, Chacko S, DiSanto ME (2004) Downregulation of cGMP-dependent protein kinase-1 activity in the corpus cavernosum smooth muscle of diabetic rabbits. Am J Physiol Regul Integr Comp Physiol 287(4): R950-60.

Cheng Chew SB, Leung PY, Fiscus RR (2003) Preincubation with atrial natriuretic peptide protects NG108-15 cells against the toxic/proapoptotic effects of the nitric oxide donor S-nitroso- N-acetylpenicillamine. Histochem Cell Biol 120(3): 163-71.

Chien JR, Aletti G, Bell DA, Keeney GL, Shridhar V, Hartmann LC (2007) Molecular pathogenesis and therapeutic targets in epithelial ovarian cancer. J Cell Biochem 102(5): 1117-29.

Deguchi A, Thompson WJ, Weinstein IB (2004) Activation of protein kinase G is sufficient to induce apoptosis and inhibit cell migration in colon cancer cells. Cancer Res 64(11): 3966-73. 
Dey NB, Busch JL, Francis SH, Corbin JD, Lincoln TM (2009) Cyclic GMP specifically suppresses Type-Ialpha cGMP-dependent protein kinase expression by ubiquitination. Cell Signal 21(6): 859-66.

Farias-Eisner R, Sherman MP, Aeberhard E, Chaudhuri G (1994) Nitric oxide is an important mediator for tumoricidal activity in vivo. Proc Natl Acad Sci U S A 91(20): 9407-11.

Fernhoff NB, Derbyshire ER, Marletta MA (2009) A nitric oxide/cysteine interaction mediates the activation of soluble guanylate cyclase. Proc Natl Acad Sci U $S$ A 106(51): 21602-7.

Fiscus RR (1988) Molecular mechanisms of endothelium-mediated vasodilation. Semin Thromb Hemost 14 Suppl: 12-22.

Fiscus RR (2002) Involvement of cyclic GMP and protein kinase G in the regulation of apoptosis and survival in neural cells. Neurosignals 11(4): 175-90.

Fiscus RR, Chan GHH, Ma ACY (2001) Diabetes mellitus (DM) causes severe impairment of hypotensive response in vivo and vasorelaxant response in vitro to the neuropeptide CGRP. In Peptides: The Wave of the Future, Lebl M, Houghten RA (eds), pp 973-974. San Diego, California, U.S.A.: American Peptide Society.

Fiscus RR, Johlfs MG (2011) Protein kinase G type-I phosphorylates c-Src at serine-17 and promotes cell survival, proliferation and attachment in human mesothelioma and non-small cell lung cancer cells. BMC Pharmacology 11(Suppl. 1): 031.

Fiscus RR, Ming SK (2000) Biology of ageing. In Medicine and Surgery in the Older Person, Pang WS, Teoh MK, Ming SK (eds), pp 29-42. Singapore: Armour Publishing Pte Ltd.

Fiscus RR, Murad F (1988) cGMP-dependent protein kinase activation in intact tissues. Methods Enzymol 159: 150-9.

Fiscus RR, Rapoport RM, Murad F (1983) Endothelium-dependent and nitrovasodilatorinduced activation of cyclic GMP-dependent protein kinase in rat aorta. J Cyclic Nucleotide Protein Phosphor Res 9(6): 415-25.

Fiscus RR, Torphy TJ, Mayer SE (1984) Cyclic GMP-dependent protein kinase activation in canine tracheal smooth muscle by methacholine and sodium nitroprusside. Biochim Biophys Acta 805(4): 382-92.

Fiscus RR, Yuen JP, Chan SL, Kwong JH, Chew SB (2002) Nitric oxide and cyclic GMP as pro- and anti-apoptotic agents. J Card Surg 17(4): 336-9.

Francis SH, Busch JL, Corbin JD, Sibley D (2010) cGMP-dependent protein kinases and cGMP phosphodiesterases in nitric oxide and cGMP action. Pharmacol Rev 62(3): 525-63.

Francis SH, Woodford TA, Wolfe L, Corbin JD (1988) Types I alpha and I beta isozymes of cGMP-dependent protein kinase: alternative mRNA splicing may produce different inhibitory domains. Second Messengers Phosphoproteins 12(5-6): 301-10.

Fraser M, Chan SL, Chan SS, Fiscus RR, Tsang BK (2006) Regulation of p53 and suppression of apoptosis by the soluble guanylyl cyclase/cGMP pathway in human ovarian cancer cells. Oncogene 25(15): 2203-12.

Fraser M, Leung B, Jahani-Asl A, Yan X, Thompson WE, Tsang BK (2003) Chemoresistance in human ovarian cancer: the role of apoptotic regulators. Reprod Biol Endocrinol 1: 66. 
Fung E, Fiscus RR, Yim AP, Angelini GD, Arifi AA (2005) The potential use of type-5 phosphodiesterase inhibitors in coronary artery bypass graft surgery. Chest 128(4): 3065-73.

Garban HJ, Bonavida B (1999) Nitric oxide sensitizes ovarian tumor cells to Fas-induced apoptosis. Gynecol Oncol 73(2): 257-64.

Hofmann F, Feil R, Kleppisch T, Schlossmann J (2006) Function of cGMP-dependent protein kinases as revealed by gene deletion. Physiol Rev 86(1): 1-23.

Hou Y, Gupta N, Schoenlein P, Wong E, Martindale R, Ganapathy V, Browning D (2006) An anti-tumor role for cGMP-dependent protein kinase. Cancer Lett 240(1): 60-8.

Isenberg JS, Ridnour LA, Perruccio EM, Espey MG, Wink DA, Roberts DD (2005) Thrombospondin-1 inhibits endothelial cell responses to nitric oxide in a cGMPdependent manner. Proc Natl Acad Sci U S A 102(37): 13141-6.

Johlfs MG, Fiscus RR (2010) Protein kinase G type-Ialpha phosphorylates the apoptosisregulating protein Bad at serine 155 and protects against apoptosis in N1E-115 cells. Neurochem Int 56(4): 546-53.

Kleinert H, Schwarz PM, Forstermann U (2003) Regulation of the expression of inducible nitric oxide synthase. Biol Chem 384(10-11): 1343-64.

Kulie T, Slattengren A, Redmer J, Counts H, Eglash A, Schrager S (2011) Obesity and women's health: an evidence-based review. J Am Board Fam Med 24(1): 75-85.

LaFevre-Bernt M, Corbin JD, Francis SH, Miller WT (1998) Phosphorylation and activation of cGMP-dependent protein kinase by Src. Biochimica et biophysica acta 1386(1): 97105.

Leung EL, Fraser M, Fiscus RR, Tsang BK (2008) Cisplatin alters nitric oxide synthase levels in human ovarian cancer cells: involvement in p53 regulation and cisplatin resistance. Br J Cancer 98(11): 1803-9.

Leung EL, Wong JC, Johlfs MG, Tsang BK, Fiscus RR (2010) Protein kinase G type Ialpha activity in human ovarian cancer cells significantly contributes to enhanced Src activation and DNA synthesis/cell proliferation. Mol Cancer Res 8(4): 578-91.

Lincoln TM, Dey N, Sellak H (2001) Invited review: cGMP-dependent protein kinase signaling mechanisms in smooth muscle: from the regulation of tone to gene expression. J Appl Physiol 91(3): 1421-30.

Nakamura T, Lipton SA (2010) Redox regulation of mitochondrial fission, protein misfolding, synaptic damage, and neuronal cell death: potential implications for Alzheimer's and Parkinson's diseases. Apoptosis 15(11): 1354-63.

Nausch LW, Ledoux J, Bonev AD, Nelson MT, Dostmann WR (2008) Differential patterning of cGMP in vascular smooth muscle cells revealed by single GFP-linked biosensors. Proc Natl Acad Sci U S A 105(1): 365-70.

Pilz RB, Casteel DE (2003) Regulation of gene expression by cyclic GMP. Circ Res 93(11): 1034-46.

Ridnour LA, Thomas DD, Switzer C, Flores-Santana W, Isenberg JS, Ambs S, Roberts DD, Wink DA (2008) Molecular mechanisms for discrete nitric oxide levels in cancer. Nitric Oxide 19(2): 73-6.

Rieder J, Jahnke R, Schloesser M, Seibel M, Czechowski M, Marth C, Hoffmann G (2001) Nitric oxide-dependent apoptosis in ovarian carcinoma cell lines. Gynecol Oncol 82(1): 172-6. 
Sato M, Nakajima T, Goto M, Umezawa Y (2006) Cell-based indicator to visualize picomolar dynamics of nitric oxide release from living cells. Anal Chem 78(24): 8175-82.

Seth D, Stamler JS (2011) The SNO-proteome: causation and classifications. Curr Opin Chem Biol 15(1): 129-36.

Soh JW, Mao Y, Kim MG, Pamukcu R, Li H, Piazza GA, Thompson WJ, Weinstein IB (2000) Cyclic GMP mediates apoptosis induced by sulindac derivatives via activation of cJun NH2-terminal kinase 1. Clin Cancer Res 6(10): 4136-41.

Thomas DD, Ridnour LA, Isenberg JS, Flores-Santana W, Switzer CH, Donzelli S, Hussain P, Vecoli C, Paolocci N, Ambs S, Colton CA, Harris CC, Roberts DD, Wink DA (2008) The chemical biology of nitric oxide: implications in cellular signaling. Free Radic Biol Med 45(1): 18-31.

Thompson WJ, Piazza GA, Li H, Liu L, Fetter J, Zhu B, Sperl G, Ahnen D, Pamukcu R (2000) Exisulind induction of apoptosis involves guanosine 3',5'-cyclic monophosphate phosphodiesterase inhibition, protein kinase $G$ activation, and attenuated betacatenin. Cancer Res 60(13): 3338-42.

Wong AS, Kim SO, Leung PC, Auersperg N, Pelech SL (2001) Profiling of protein kinases in the neoplastic transformation of human ovarian surface epithelium. Gynecol Oncol 82(2): 305-11.

Wong JC, Fiscus RR (2010) Protein kinase G activity prevents pathological-level nitric oxideinduced apoptosis and promotes DNA synthesis/cell proliferation in vascular smooth muscle cells. Cardiovasc Pathol 19(6): e221-31.

Wong JC, Fiscus RR (2011) Essential roles of the nitric oxide (NO)/cGMP/protein kinase G type-Ialpha (PKG-Ialpha) signaling pathway and the atrial natriuretic peptide (ANP)/cGMP/PKG-Ialpha autocrine loop in promoting proliferation and cell survival of OP9 bone marrow stromal cells. J Cell Biochem 112(3): 829-39. 


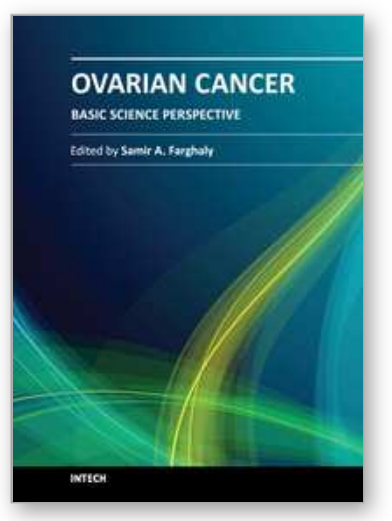

\author{
Ovarian Cancer - Basic Science Perspective \\ Edited by Dr. Samir Farghaly
}

ISBN 978-953-307-812-0

Hard cover, 406 pages

Publisher InTech

Published online 17, February, 2012

Published in print edition February, 2012

Worldwide, Ovarian carcinoma continues to be responsible for more deaths than all other gynecologic malignancies combined. International leaders in the field address the critical biologic and basic science issues relevant to the disease. The book details the molecular biological aspects of ovarian cancer. It provides molecular biology techniques of understanding this cancer. The techniques are designed to determine tumor genetics, expression, and protein function, and to elucidate the genetic mechanisms by which gene and immunotherapies may be perfected. It provides an analysis of current research into aspects of malignant transformation, growth control, and metastasis. A comprehensive spectrum of topics is covered providing up to date information on scientific discoveries and management considerations.

\title{
How to reference
}

In order to correctly reference this scholarly work, feel free to copy and paste the following:

Ronald R. Fiscus, Elaine L. Leung, Janica C. Wong and Mary G. Johlfs (2012). Nitric Oxide/Protein Kinase GI $\alpha$ Promotes c-Src Activation, Proliferation and Chemoresistance in Ovarian Cancer, Ovarian Cancer - Basic Science Perspective, Dr. Samir Farghaly (Ed.), ISBN: 978-953-307-812-0, InTech, Available from: http://www.intechopen.com/books/ovarian-cancer-basic-science-perspective/nitric-oxide-protein-kinase-gialpha-promotes-c-src-activation-proliferation-and-chemoresistance-in-

\section{INTECH}

open science | open minds

\author{
InTech Europe \\ University Campus STeP Ri \\ Slavka Krautzeka 83/A \\ 51000 Rijeka, Croatia \\ Phone: +385 (51) 770447 \\ Fax: +385 (51) 686166 \\ www.intechopen.com
}

\author{
InTech China \\ Unit 405, Office Block, Hotel Equatorial Shanghai \\ No.65, Yan An Road (West), Shanghai, 200040, China \\ 中国上海市延安西路65号上海国际贵都大饭店办公楼 405 单元 \\ Phone: +86-21-62489820 \\ Fax: +86-21-62489821
}


(C) 2012 The Author(s). Licensee IntechOpen. This is an open access article distributed under the terms of the Creative Commons Attribution 3.0 License, which permits unrestricted use, distribution, and reproduction in any medium, provided the original work is properly cited. 